\title{
State Variables in Saturated-Unsaturated Soil Mechanics
}

\author{
D.G. Fredlund
}

\begin{abstract}
The description of the stress state in soils is the foundational point around which an applied science should be built for engineering practice. The stress state description has proven to be pivotal for saturated soil mechanics and the same should be true for unsaturated soil mechanics. Continuum mechanics sets forth a series of principles upon which a common science base can be developed for a wide range of materials. The principles require that there be a clear distinction between state variables and constitutive relations. Constitutive relations relate state variables and incorporate material properties. State variables, on the other hand, are independent of the material properties. It has been possible to maintain a clear distinction between variables of state and constitutive relations in the development of saturated soil mechanics and the same should be true for unsaturated soil mechanics. This paper presents a description of the source and character of stress state variables for saturated and unsaturated soils. The descriptions are consistent with the principles of multiphase continuum mechanics and provide an understanding of the source and importance of stress state variables.
\end{abstract}

Keywords: state variables, soil suction, constitutive relations, continuum mechanics.

\section{Introduction}

Karl Terzaghi (1883-1963) is recognized as the "Father of Soil Mechanics". He defined the term "effective stress" as the variable around which the physical behaviour of a saturated soil can be described. Effective stress was defined as $\left(\sigma-u_{w}\right)$ where $\sigma$ was total stress and $u_{w}$ was the pore-water pressure. The recognition of effective stress as the state variable controlling the equilibrium of the soil structure of a saturated soil elevated saturated soil mechanics from an art to a science. Effective stress provided a means whereby the physical behaviour of a saturated soil could be described. The effective stress variable was independent of the properties of the soil. The effective stress variable has become the rallying point and the unifying variable for understanding volume change, distortion, shear strength, seepage and other physical process in saturated soils. The use of the effective stress variable in saturated soil mechanics was clearly illustrated for various soil mechanics problems in Terzaghi's first textbook, "Theoretical Soil Mechanics" published in 1943.

This paper revisits issues relevant to the description of the stress state of particulate materials; in particular, saturated and unsaturated soils. The fundamental basis for use of stress state variables in soil mechanics is explained. The fundamental basis for the use of effective stress for saturated soils is presented first followed by a similar description of the stress state variables for unsaturated soils. The emphasis is on state variables associated with stresses; however, it is recognized that there are also other state variables such as those required for mapping deformations and distortions of particulate, multiphase systems. These are referred to as deformation state variables but their description is outside the scope of this paper.

\section{Terzaghi’s Description of Effective Stress}

In 1936, Terzaghi described and justified the use of the effective stress variable for saturated soils as follows. Terzaghi (1936) wrote, "The stresses in any point of a section through a mass of soil can be computed from the total principal stresses, $\sigma_{1}, \sigma_{2}, \sigma_{3}$, which act at this point. If the voids of the soil are filled with water under a stress, $u_{w}$, the total principal stresses consist of two parts. One part, $u_{w}$, acts in the water and in the solid in every direction with equal intensity (emphasis added). It is called the neutral (or pore-water) pressure. The balance $\sigma_{1}{ }^{\prime}=\sigma_{1}-u_{w}, \sigma_{2}{ }^{\prime}=\sigma_{2}-u_{w}$, $\sigma_{3}{ }^{\prime}=\sigma_{3}-u_{w}$ represent an excess over the neutral stress, $u_{w}$, and has its seat exclusively in the solid phase of the soil (emphasis added). All the measurable effects of a change in shearing resistance are exclusively due to changes in the effective stress, $\sigma_{1}{ }^{\prime}, \sigma_{2}{ }^{\prime}, \sigma_{3}{ }^{\prime}$,

The above paragraph sets forth the meaning of the effective stress variable. Effective stress is the difference between the total stresses and pore-water pressure in three orthogonal directions. The three principal directions arise from the Cartesian coordinate system associated with three-dimensional space. Stresses in three directions can be combined to form a stress tensor that defines the stress state at a point in saturated soil. The stress tensor with components, $\left(\sigma_{1}-u_{w}\right),\left(\sigma_{2}-u_{w}\right)$, and $\left(\sigma_{3}-u_{w}\right)$, form the variables that control the equilibrium of the soil structure. The words "soil structure" is used in the sense of referring to the arrangement of the soil solids. The effective stress variables are associated with equilibrium conditions and can therefore be used to describe the behaviour of the soil structure of a saturated soil. Stated another way, the effective stress variables can be used to describe changes from the equilibrium state in a saturated soil.

Delwyn G. Fredlund, PhD., Golder Associates Ltd., 1721 - th $^{\text {th }}$ Street East, Saskatoon, S7H 0T4 SK, Canada. e-mail: del_fredlund@ golder.com. Invited Article, no discussion. 
There are two statements in Terzaghi's description of effective stress that are noteworthy because of their consistency with the principles of multiphase continuum mechanics. The first statement notes that the water pressure "acts in the water and in the solid in every direction with equal intensity". This statement is consistent with the concept of superposition of equilibrium stress fields in multiphase continuum mechanics (Fung, 1965). The second statement notes that the difference between the total stress and porewater pressure "has its seat exclusively in the solid phase of the soil". In other words, the effective stress variable is linked to the soil structure (or the arrangement of soil solids). It is also noteworthy that while these statements are consistent with continuum mechanics principles, Terzaghi wrote these statements when continuum mechanics was still in a formative stage.

Terzaghi's statement describing effective stress remains consistent with the principles of multiphase continuum mechanics attesting to the wisdom of his original description.

\section{What is Effective Stress?}

- History has shown that even though the original definition of effective stress was presented with clarity, the term "effective stress" has still suffered considerable misunderstanding. As a teacher of soil mechanics, students have sometimes inquired of the author as to the physical meaning and source of "effective stress". Effective stress has been highly esteemed and almost treated as a sacrament within geotechnical engineering but the questions remains, "What is the source and physical meaning of effective stress?" Effective stress has been described in numerous ways; some descriptions being inaccurate while others are reasonable and acceptable. Listed below are some of the descriptive terms associated with effective stress along with a brief description of how each term is used.

- 1) Is effective stress an equation? It can be argued that "effective stress" is an equation because it has an equal sign. However, it can also be argued the effective stress symbol is simply the difference between two variables; that difference being called effective stress. The dictionary defined an equation as "a statement that the values of two mathematical expressions are equal" (Wikipedia, 2013). The use of the word equation for the effective stress variable may have led geotechnical engineers to think there is additional physical meaning behind the use of the term "effective stress". The use of the word, "equation" may have fuelled the search for refinements to the equation for both saturated and unsaturated soils.

- 2) Is effective stress a law? This question could also be presented in a slightly different manner as, "Should effective stress strictly be referred to as a physical law?" And if effective stress is a law, then what is the physical process behind the law. Maybe the word law once again elevates the term effective stress to a perceived level that is not justifiable. Or is the only law involved behind the term effective stress, the summation or equilibrium of forces associated with Newtonian mechanics?

- 3) Is effective stress a constitutive equation? The word constitutive implies the incorporation of one or more soil properties. Consequently, it would seem clear to come to the conclusion that effective stress should not be referred to as a constitutive equation. However, the history of soil mechanics shows that there have been attempts to bring soil properties into the description of effective stress. It is important to remember that variables associated with state cannot be constitutive in character.

- 4) Is effective stress a concept? The concept could be stated as follows, "If one changes effective stress, it should be anticipated that something might happen to the equilibrium of the soil structure". For example, it is anticipated that there may be a change in volume of the saturated soil. On the converse, if effective stress is not changed there should not be a change in volume. The linkage between changes in stress state and changes in equilibrium of the soil structure can be referred to as the effective stress concept. Stated another way, the equilibrium of the soil structure is perturbed when 'effective stresses' in a saturated soil are changed.

- 5) Is effective stress a principle? The principle of effective stress could also be described in a manner similar to that used for the concept of effective stress. The principle of effective stress would state, "If effective stresses are changed, something should happen to the equilibrium of the soil structure and if effective stresses are not changed, there should be no change in the equilibrium of the soil structure of a saturated soil". Changes in the saturated soil structure may be small but equilibrium conditions have been perturbed when the stress state is changed.

- 6) Is effective stress a stress state variable? State variables should be defined independent of material properties (i.e., non-material based variables). In this sense "effective stress" qualifies as a stress state variable. It can also be reasoned that effective stress applies in each of the Cartesian coordinate directions since equilibrium conditions must be satisfied in all three orthogonal directions.

- 7) Is effective stress a tensor? A tensor is a 3 by 3 matrix which arises out of consideration of three orthogonal directions. The three-dimensions define space. Effective stress can also be visualized as having three principal directions where there are only normal stresses and no shear stresses. The stress tensor contains effective stress variables along the trace and as such, effective stress has three spatial components.

- 8) Is effective stress only for saturated soils? The term effective stress was initially defined solely for saturated soils. As shown later in this paper, effective stress does not qualify as an adequate term to describe the stress 
state of an unsaturated soil. However, the principles of continuum mechanics allow for the use of more than one tensor (or combination of state variables) for the description of stress state.

The following responses to the above-mentioned questions should apply to the use of the words, "effective stress", if the strict definitions from continuum mechanics are applied.

1) Is effective stress an equation? No

2) Is effective stress a law? No

3) Is effective stress a constitutive equation? No

4) Is effective stress a concept? Yes

5) Is effective stress a principle? Yes

6) Is effective stress a stress state variable? Yes

7) Is effective stress a tensor? Yes

8) Is effective stress only for saturated soils? Yes

There may be some room for debate regarding the usage of some of the effective stress terms; however, as far as possible it would appear to be best to remain consistent with continuum mechanics' terminology and definitions.

The question might rightfully be asked, "Where does effective stress come from and does it have a physical basis?" There would appear to be a sound continuum mechanics basis for the "effective stress" variable for saturated soil but that will be presented later in the paper. The same continuum mechanics principles and definitions can also be applied to unsaturated soils and the result is the realization that more than one independent state variable is required to describe the stress state of an unsaturated soil.

\section{Definition of Key Technical Terms from Continuum Mechanics}

There are several technical terms and definitions that are well accepted within continuum mechanics that need to be described in order to understand the characteristics of state variables (Fung, 1965; 1977). Continuum mechanics has attempted to define a consistent set of terms that can be applied to all types of material behaviour. The terminology applies to single and multiphase particulate media. It applies to solids as well as fluids. It applies to elastic behaviour, plastic behaviour and viscous behaviour. The key variables that need to be defined are as follows:

State Variables: Are variables independent of material properties required for the characterization of a system (e.g., pressure, temperature, volume, time, etc.). These variables are defined independent of the physical properties of the material.

Stress State Variables: Are independent of material properties required for the characterization of force (or stress) equilibrium conditions.

Deformation State Variables: Are independent of material properties variables required for the description of deformations, distortions and deviations from an initial state.
Constitutive Relations: Single-valued equations expressing the relationship between state variables. Constitutive relations incorporate the physical properties of a material corresponding to a particular process to be simulated.

\section{The Search for an Equation}

The original definition of effective stress for saturated soil behaviour has been the single most important concept behind the development of saturated soil mechanics. While the original description of effective stress by Terzaghi (1936) is clear, there is a subtle variation of the definition that has been included in virtually every soil mechanics textbook. The variation arises out of an attempt to describe the meaning of effective stress. The variations are often put in the context of a "refinement" to the effective stress equation; however, the revisions to the effective stress equations would appear to constitute a step away from the concepts associated with continuum mechanics and an accurate application of soil mechanics. One of the suggested revisions to the effective stress equation involved the use of a wavy plane passed through the points of contact in a saturated particulate medium.

Most soil mechanics' textbooks have a figure that shows a particulate media with a wavy plane passed between the contact points between particles (Fig. 1). The figures common to most soil mechanics textbooks portray what is referred to as the "wavy plane" concept. A portion of the wavy plane is shown to pass through the contact points between particles while the remainder of the plane passes through water in the voids. The common explanations suggest that static equilibrium can be applied across the wavy plane over a unit area. This figure is then treated as a free-body diagram and forces are summed in the vertical direction across the wavy plane.

The analysis usually goes on to justify the form of the effective stress equation and suggests that an area correction should be applied to the effective stress equation to make is more refined and accurate. It is also often suggested that the area correction in the effective stress equation is small and its usage is not necessary. It is important to fur-

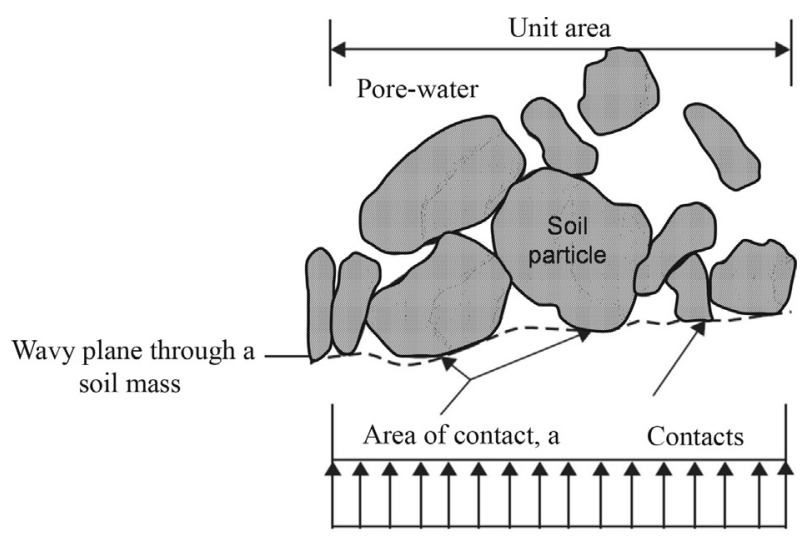

Figure 1 - Illustration of the use of the wavy plane concept. 
ther investigate the wavy plane analysis to ascertain whether the wavy plane analysis is fundamentally flawed.

There appears to be a fundamental flaw with the above-mentioned analysis in the sense that a wavy plane passed through a soil mass does not represent a legitimate free-body diagram (Fung, 1977). Even the use of a linear plane surface passed through a continuum does not represent a legitimate free-body diagram. In order to qualify as an acceptable free-body diagram in static mechanics, the free-body must have spatial variation (Fung, 1977). If a wavy plane does not constitute an acceptable free-body diagram then any subsequent mathematical manipulations that may be undertaken are unacceptable.

\section{Steps Taken in the Wavy Plane Analysis}

The mathematical steps that are adhered to in the wavy plane analysis are presented in detail in order to examine aspects of the analysis that are unacceptable. The examination of the wavy plane analysis is important because of the significant impact that this analysis has had on attempting to understand and define the stress state for unsaturated soils.

Forces are summed in the vertical direction, over a unit area with the understanding that the sum of the forces of the parts must equal the total force (Fig. 1).

$$
a \sigma_{i}+(1-a) u_{w}=\sigma
$$

where $a=$ area of contact, $\sigma_{i}=$ inter-particle (or intergranular) stress, $u_{w}=$ pore-water pressure, and $\sigma=$ total stress,

Multiplying out the terms in Eq. 1 gives,

$$
a \sigma_{i}+u_{w}-a u_{w}=\sigma
$$

The term effective stress is assumed to be equivalent to the inter-granular stress multiplied by the area of contact giving,

$$
a \sigma_{\mathrm{i}}=\sigma^{\prime}
$$

The " $a$ " variable is a ratio of areas but it is also a material property. The above-mentioned conversion has changed a force to a stress. Rearranging the above equation gives the effective stress equation with an area of contact term.

$$
\sigma^{\prime}=\left(\sigma-u_{w}\right)+a u_{w}
$$

The effective stress equation can be written as follows provided it is assumed that the area of contact is small.

$$
\sigma^{\prime}=\left(\sigma-u_{w}\right)
$$

At this point it is important to re-visit the abovementioned steps and identify the shortcomings of such an analysis.

\section{Inherent Limitations Associated with the Wavy Plane Analysis}

There are a number of inherent limitations associated with the wavy plane analysis. The first question that might be asked is, "Why is a (wavy) plane not an acceptable free-body diagram?" In response to this question, let us consider the simple case of a ladder leaning against a wall as shown in Fig. 2.

The central diagram showing the forces on the leaning ladder is an acceptable free-body diagram. However, it is not possible to draw a free-body diagram of the plane where the ladder touches the wall. It is possible to state that "action" is equal to "reaction" of the point where the ladder touches the wall but is not possible to apply Newton's second law of statics. It is important to recall Newton's three laws of statics and the reason why an independent law of "action" is equal to "reaction" was needed.

First Law: Bodies in motion will remain in motion unless it is acted upon by an external force.

Second Law: The acceleration of an object is dependent upon thenet forceacting upon the object and the mass of the object. Consequently, when an object is in static equilibrium the summation of forces and moments are equal to zero.

Third Law: For every action there must be an equal and opposite reaction.

Newton's third law can be applied to stresses on a plane passed through an object or when one object interacts with another object. Newton's third law constitutes a statement of equivalence when applied to a plane. It is not possible to use the third law as a basis for a static equilibrium proof. Rather, it is simply possible to let one condition be equal to another condition. The wavy plane passed through a multiphase system such as soil cannot be used as a static equilibrium proof (i.e., Newton's second law), because there is no spatial variation of forces.

The second question to address is, "Why is a wavy plane unacceptable?" A wavy plane builds bias into the analysis. Using a wavy plane goes contrary to the basic definition of a continuum. Any plane passed through a multiphase material must be unbiased (Truesdell, 1966; Fung, $1969 ; 1977)$. The definition of a continuum requires that the porosity of a multiphase material must be equal with re-

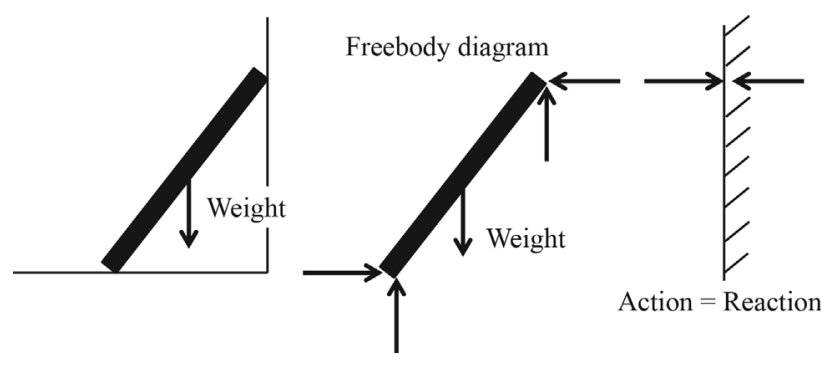

Figure 2 - Free-body diagram of a ladder leaning against a wall. 
spect to volume porosity (of a representative elemental volume, REV), and area porosity (i.e., the sides of the REV). The definition of a continuum is described in terms of the density function with respect to each phase of a multiphase system being constant. A wavy plane creates a problem in that it builds bias into the analysis and contradicts the definition of a continuum.

The definition of a continuum requires that the sum of the components of a multiphase system must be the same on a volume and area basis. A saturated soil consists of solids and water with the sum of the parts equal to the whole, both in terms of volume and area. Therefore, the plane cannot be biased.

$$
\begin{aligned}
& V_{s}+V_{w}=V_{t}(\text { by volume }) \\
& \left.a_{s}+n_{w}=1 \text { (by area }\right)
\end{aligned}
$$

where $V_{s}=$ volume of solids, $V_{w}=$ volume of water, $a_{s}=$ area of solids, and $n_{w}=$ porosity.

The equilibrium of two-dimensional (or three-dimensional) stress fields can be used to verify the acceptability of the effective stress variable for saturated soils. The multi-dimensional force equilibrium analysis illustrates that there is no need to apply an area of contact correction to the effective stress variable.

There have also been other attempts to refine Terzaghi's original effective stress variable; however, in each case, a soil property has been incorporated into the stress variable. In so doing the stress variable has become "constitutive" in nature and no longer rigorously qualifies as a state variable.

\section{Acceptable Stress Fields for the Verification of the Stress State of Multiphase Systems}

There are two types of stress fields that can be placed on a representative elemental volume, REV, of a continuum; namely, i) body forces per unit volume, and ii) surface tractions. Each phase of a multiphase system has an independent stress field. The stress fields can be viewed as being superimposed when several phases are involved (Truesdell, 1966). The continuum mechanics representation of stress fields for a one phase solid will first be presented followed by consideration of a saturated soil (i.e., a two phase system). And finally, consideration will be given to the stress fields for an unsaturated soil system.

\section{Representation of Stress Fields for a One Phase Continuum}

A stress field acting in a particular direction can be represented mathematically as a linearly varying field across a REV as shown in Fig. 3 (Truesdell, 1966). When forces are summed in the vertical direction, equilibrium is maintained since the variation of the stress field in the $y$-direction is taken into consideration. It can also be seen that a

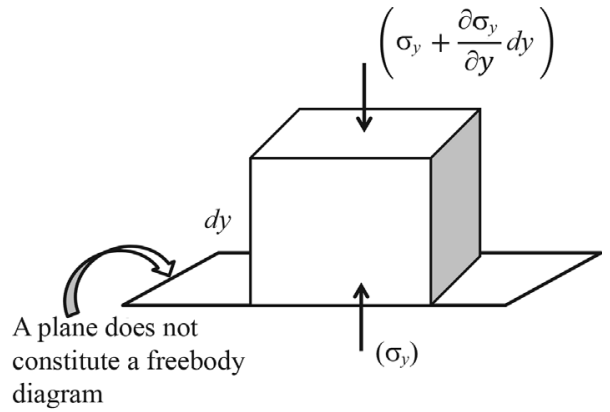

Figure 3 - Illustration of a multi-dimensional free-body diagram showing a stress field.

plane through the bottom surface of the REV cannot be used to satisfy equilibrium considerations. The same equilibrium analysis can be extended to the three coordinate directions as shown in Fig. 4.

Equilibrium equations for a one phase solid can be written by summing forces in each of the Cartesian coordinate directions (Fung, 1969; 1977). The equilibrium equations for the $x$-, $y$-, and $z$-directions, respectively, are:

$$
\begin{aligned}
& \left(\frac{\partial \sigma_{x}}{\partial x}+\frac{\partial \tau_{y x}}{\partial y}+\frac{\partial \tau_{z x}}{\partial z}\right) d x d y d z=0 \\
& \left(\frac{\partial \tau_{x y}}{\partial x}+\frac{\partial \sigma_{y}}{\partial y}+\frac{\partial \tau_{z y}}{\partial z}+\rho g\right) d x d y d z=0 \\
& \left(\frac{\partial \tau_{x z}}{\partial x}+\frac{\partial \tau_{y z}}{\partial y}+\frac{\partial \sigma_{z}}{\partial z}\right) d x d y d z=0
\end{aligned}
$$

where $\sigma_{x}=$ total normal stress in the $x$-direction, $\sigma_{y}=$ total normal stress in the $y$-direction, $\sigma_{z}=$ total normal stress in the $z$-direction, $\tau_{y x}=$ shear stress on the $y$-plane in the $x$-direction, $\tau_{x y}=$ shear stress on the $x$-plane in the $y$-direction, $\tau_{z y}=$ shear stress on the $z$-plane in the $y$-direction, $\tau_{y z}=$ shear stress on the $y$-plane in the $z$-direction, $\tau_{x z}=$ shear stress on the $x$-plane in the $z$-direction, and $\tau_{z x}=$ shear stress on the $z$-plane in the $x$-direction.

The surface tractions found in the equilibrium equation can be extracted to form a 3 by 3 matrix, (i.e., a tensor) as shown in Eq. 11. The tensor represents the stress state at a point in any one phase solid.

$$
\left[\begin{array}{lll}
\sigma_{x} & \tau_{y x} & \tau_{z x} \\
\tau_{x y} & \sigma_{y} & \tau_{z y} \\
\tau_{x z} & \tau_{y z} & \sigma_{z}
\end{array}\right]
$$

The stress tensor can also be plotted on a cube as a representation of the stress state in the one phase solid (Fig. 5). A one phase solid could consist of any material ranging from steel to cheese. The form of the stress state variables is dictated largely by the number of phases involved. 


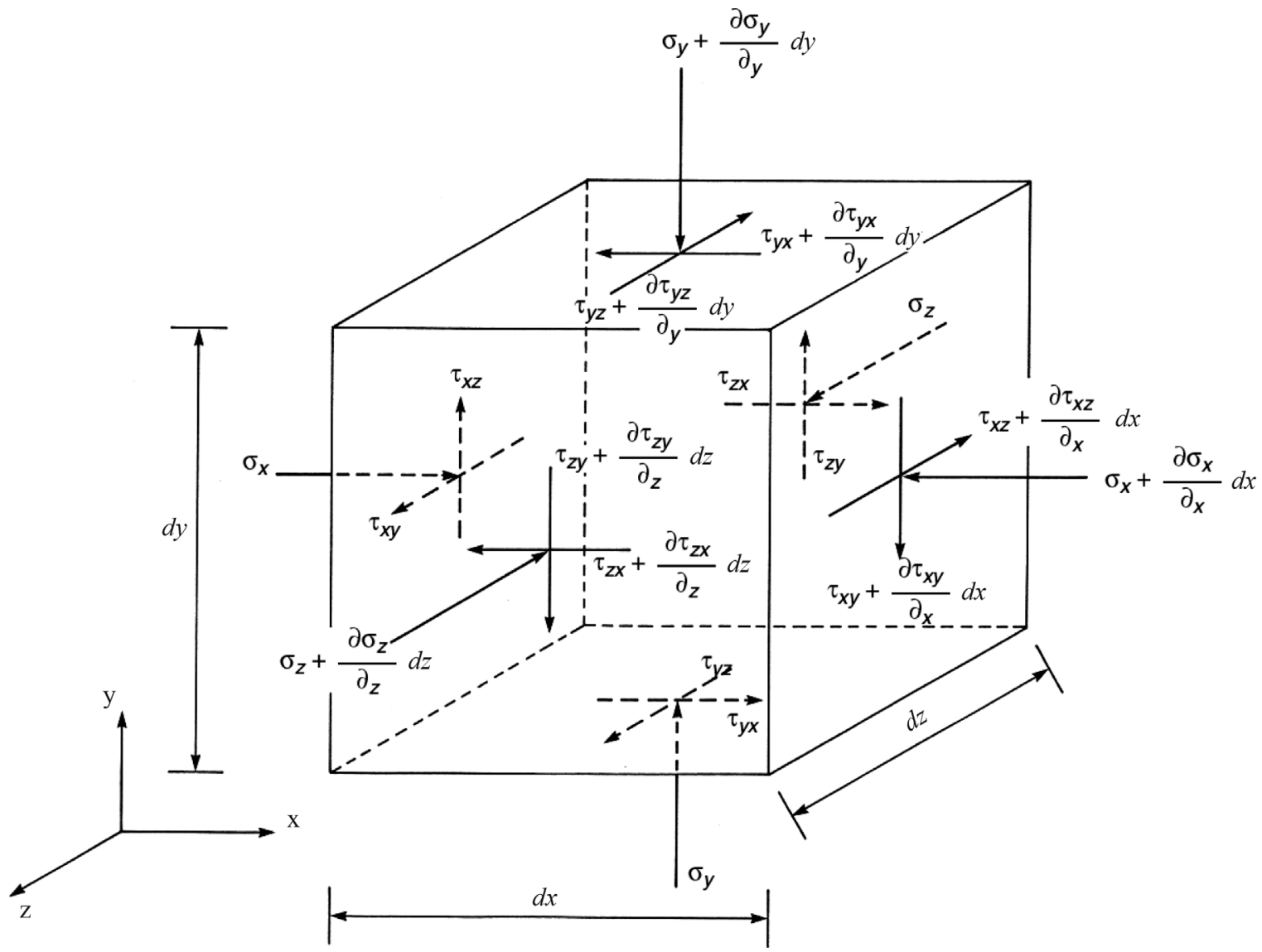

Figure 4 - Equilibrium stress fields in three Cartesian coordinate directions for a one phase solid.

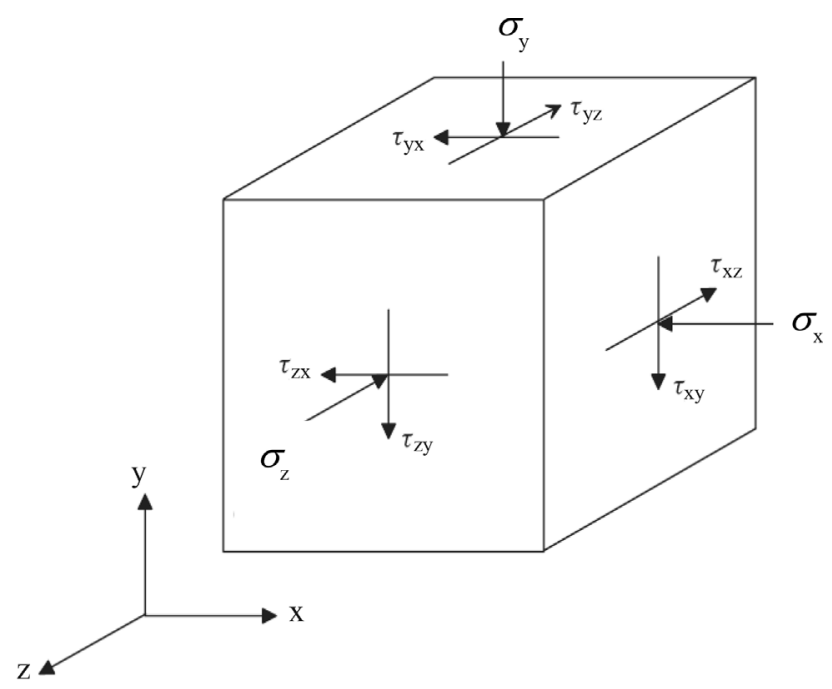

Figure 5 - Stress state at a point in a one phase solid.

\section{Stress Fields for the Verification of Effective Stress for a Saturated Soil}

A stress field exists for each phase of a multiphase system. A saturated soil has a stress field associated with the water phase. Terzaghi (1936) clearly explained that the water phase stress field acts in the water and through the solid phase. The solid phase consisting of an arrangement of particles also has an independent stress field. In fact, it is the stress field associated with the soil solids that represents the equilibrium of soil structure. Unfortunately, the stress field associated with the soil structure cannot be directly measured. On the other hand, it is possible to write a stress field that represents the summation of all the individual stress fields. This stress field can be referred to as the overall stress field or the total stress field. The total stress field has the same form as the stress field equation written for a one phase solid. The summation of the superimposed coincident, equilibrium stress fields associated for each phase of a multiphase system form the overall equilibrium stress field.

The stress field equation (Eq. 12), for the water phase is illustrated by the free-body diagram shown in Fig. 6 for the $y$-direction. The free-body diagram for the water phase must also have two added body forces. One body force is for the gravity force associated with water, $n_{w} \rho_{w} g$, while the other body force is the seepage force, $F_{s y}{ }^{w}$, which must be taken into consideration when the water phase is separated from the soil solids phase.

$$
\frac{n_{w} \partial u_{w}}{\partial y}+n_{w} \rho_{w} g+F_{s y}^{w}=0
$$




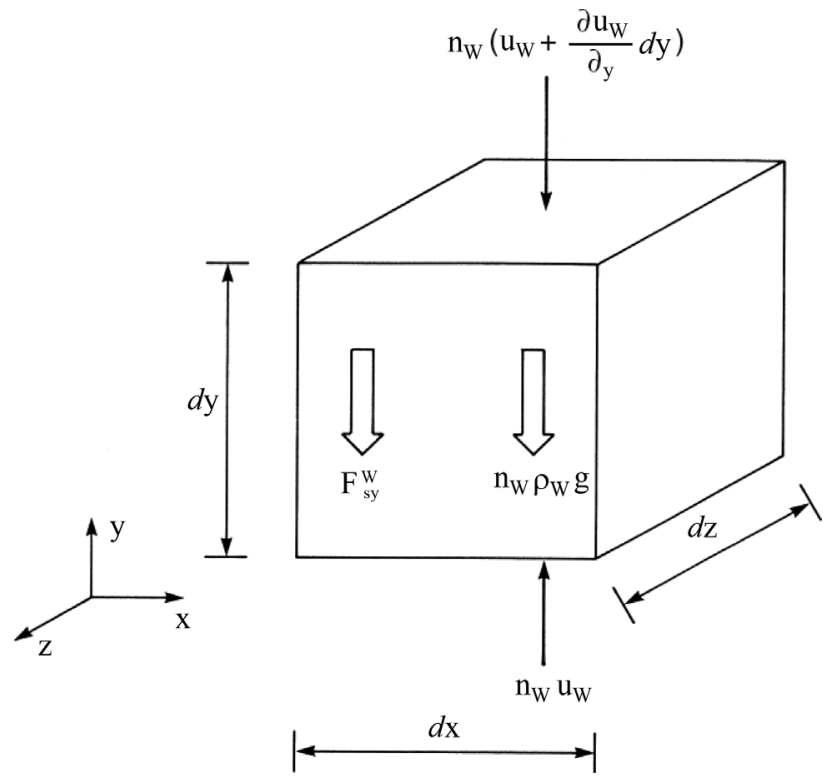

Figure 6 - Equilibrium stress field associate with the water phase of a saturated soil.

Equilibrium equations for the $x$ - and $z$-directions can be written in a similar manner.

Since the sum of the individual stress fields must be equal to the overall stress field, it is possible to write the equilibrium stress field for the soil solids phase as the difference between the overall stress field and the water phase stress field. These equations are shown for the $x$-, $y$-, and $z$-directions, respectively, are shown in Eqs. 13, 14, and 15.

$$
\begin{aligned}
& \frac{\partial\left(\sigma_{x}-u_{w}\right)}{\partial x}+\frac{\partial \tau_{y x}}{\partial y}+\frac{\partial \tau_{z x}}{\partial z}+\frac{n_{s} \partial u_{w}}{\partial x}+n_{s} \rho_{s} g+F_{s x}^{w}=0 \\
& \frac{\partial \tau_{x u}}{\partial x}+\frac{\partial\left(\sigma_{y}-u_{w}\right)}{\partial y}+\frac{\partial \tau_{z y}}{\partial z}+\frac{n_{s} \partial u_{w}}{\partial y}+n_{s} \rho_{s} g+F_{s y}^{w}=0 \\
& \frac{\partial \tau_{x z}}{\partial x}+\frac{\partial \tau_{y z}}{\partial y}+\frac{\partial\left(\sigma_{z}-u_{w}\right)}{\partial z}+\frac{n_{s} \partial u_{w}}{\partial z}+n_{s} \rho_{s} g+F_{s z}^{w}=0
\end{aligned}
$$

The surface tractions found in the equilibrium equation can be extracted to form a 3 by 3 matrix, (i.e., a tensor) as shown in Eq. 16. The tensor represents the stress state of the soil structure at a point in the two phase material such as a saturated soil.

$$
\left[\begin{array}{ccc}
\left(\sigma_{x}-u_{w}\right) & \tau_{y x} & \tau_{z x} \\
\tau_{x y} & \left(\sigma_{y}-u_{w}\right) & \tau_{z y} \\
\tau_{x z} & \tau_{y z} & \left(\sigma_{z}-u_{w}\right)
\end{array}\right]
$$

A stress tensor can also be plotted on a cube to represent the soil solids stress state for a saturated soil (Fig. 7). The stress tensor should represent the stress state variables controlling the solid phase of a two phase system.

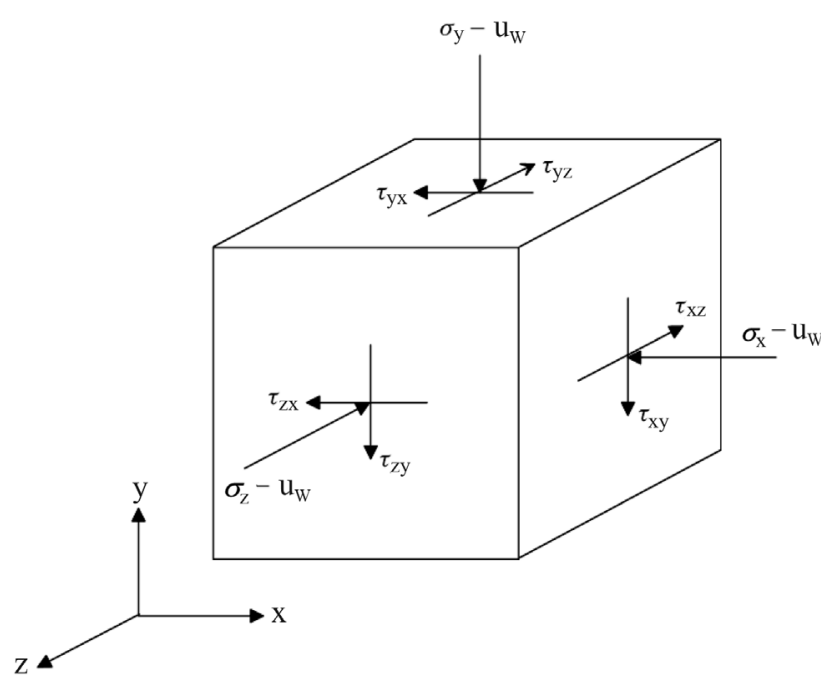

Figure 7 - Stress state at a point for the solids phase of a two phase saturated soil.

\section{Stress Fields for a Dry Soil}

Equilibrium equations can also be written for a completely dry soil with a pore-air pressure, $u_{a}$. In this case the soil structure equilibrium equations are the same as Eqs. 13, 14 and 15 with the exception that pore-air pressure is substituted for pore-water pressure. The stress tensor for the dry soil is shown as Eq. 17 and the stress state at a point is shown in Fig. 8. Even in the case of a highly compressible pore fluid, the description of the stress state is independent of the properties of the pore fluid.

$$
\left[\begin{array}{ccc}
\left(\sigma_{x}-u_{a}\right) & \tau_{y x} & \tau_{z x} \\
\tau_{x y} & \left(\sigma_{y}-u_{a}\right) & \tau_{z y} \\
\tau_{x z} & \tau_{y z} & \left(\sigma_{z}-u_{a}\right)
\end{array}\right]
$$

The superposition of independent, coincident equilibrium stress fields can also be applied to multiphase systems with more than two phases, for example, a four phase system such as an unsaturated soil (Fredlund, 1973). A review of the research literature shows that historical, fundamental studies of unsaturated soil behaviour were primarily interested in finding an equation that could be used to describe the physical behaviour of an unsaturated soil. The search seemed to be for a single-valued equation rather than a search for independent stress state variables.

\section{The Rearch for an Effective Stress Equation for Unsaturated Soils}

Effective stress equations proposed for unsaturated soils shows the primary focus of a variety of researchers. The search started in the late 1950s and has continued to the present. The earliest proposed equation, and the best known of all equations is Bishop's effective stress equation (1959).

$$
\sigma^{\prime}=\left(\sigma-u_{a}\right)+\chi\left(u_{a}-u_{w}\right)
$$




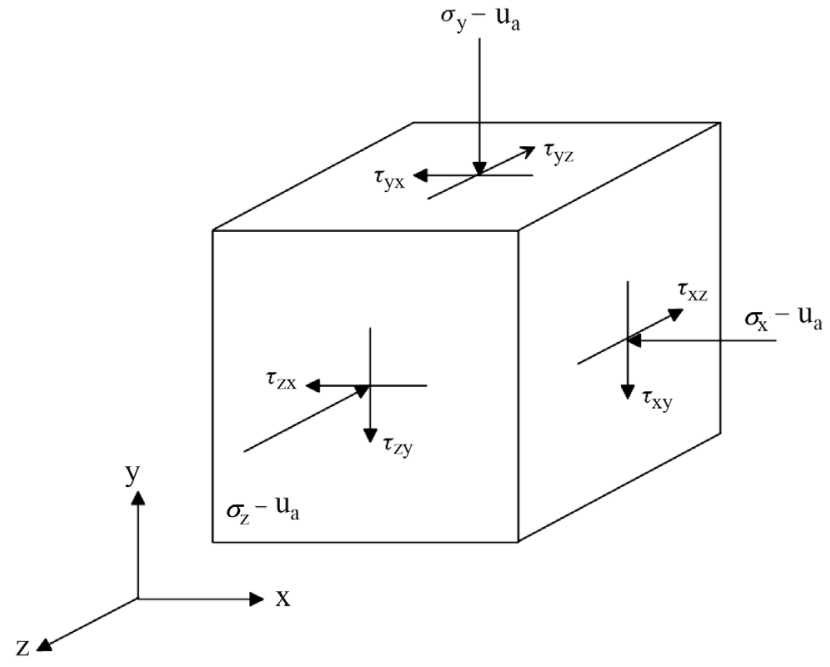

Figure 8 - Stress state for the soil structure of a completely dry particulate medium.

where $\sigma=$ effective stress, $\sigma=$ total stress, $u_{w}=$ pore-water pressure, $u_{a}=$ pore-air pressure, and $\chi=$ soil parameter related to the degree of saturation of the soil, ranging from zero to 1.0

Other effective stress equations have also been proposed (Croney et al., 1958; Jennings 1961; Aitchison, 1961). All of the proposed equations are similar in form and become equal when the pore-air pressure is atmospheric. Also common to all equations is the incorporation of a soil property into the description of the stress state of an unsaturated soil. The soil property makes all equations take on the character of a constitutive equation; thus violating the fundamental separation of state variables and constitutive behaviour.

With time the degree of saturation, $S$, of the soil has often been used in place of the $\chi$ soil parameter, and the equations have been written in a tensor form (Jommi, 2000). In so doing, the degree of saturation has become an approximation for the $\chi$ parameter but the equation still has a constitutive nature.

Wavy planes have also been passed through an unsaturated soil in an attempt to justify the so-called effective stress equations for an unsaturated soil. The fallacy of such an approach is the same as explained above for a saturated soil.

Over the same period of time when effective stress equations have been proposed for unsaturated soils, there have also been researchers who have maintained that the stress variables, $\left(\sigma-u_{a}\right)$ and $\left(u_{a}-u_{w}\right)$ should be treated as independent stress state variables and used as such to form constitutive equations that are then used in theoretical formulations. As early as 1941, Biot used the stress state variables in an independent manner in his formulation of the theory of consolidation of an unsaturated soil. Coleman (1962), Matyas \& Radakrishna (1968), and Fredlund \&
Morgenstern (1977) advocated the use of independent stress state variables.

\subsection{Examination of the wavy plane analysis for an un- saturated soil}

A wavy plane passed through an unsaturated soil will pass through the air and water phases in addition to the soil-to-soil points of contact as shown in Fig. 9. Once again, the wavy plane does not constitute a legitimate free-body diagram and is therefore unacceptable for verification purposes. However, let us follow the steps common to this derivation to observe the fallacies associated with the wavy plane analysis.

The wavy plane analysis does not even qualify as an approximation of the physics behind the stress state of an unsaturated soil. Rather, the wavy plane analysis is a violation of statics at its most fundamental level. The rationale; however, is as follows. The attempt to sum forces in the vertical direction across a plane yields the following equation.

$$
\sigma=\sigma_{i} a+u_{w}\left(1-a-a_{a}\right)+u_{a}\left(1-a-a_{w}\right)
$$

where $a=$ area of contact between particles along the wavy plane, $a_{w}=$ portion of the unit area that is in water, and $a_{a}=$ portion of the unit area that is in air.

Multiplying out the terms in Eq. 19, collecting terms and setting $\sigma$ ' equal to $\sigma_{i} a$ gives the following equation.

$$
\sigma=\sigma^{\prime}+u_{w}-a_{a} u_{w}+u_{a}-a_{w} u_{a}+a u_{w}-a u_{a}
$$

The terms in Eq. 20 can be collected and solved for the effective stress term after making the assumption that the area of contact between solid particles approaches zero.

$\sigma^{\prime}=\left(\sigma-u_{a}\right)+a_{w} u_{a}+\left(a_{a}-1\right) u_{w}$

A further collection of terms gives.

$$
\sigma^{\prime}=\left(\sigma-u_{a}\right)+a_{w}\left(u_{a}-u_{w}\right)
$$

Setting the area of the plane passing through water equal to the degree of saturation of the soil gives an equa-

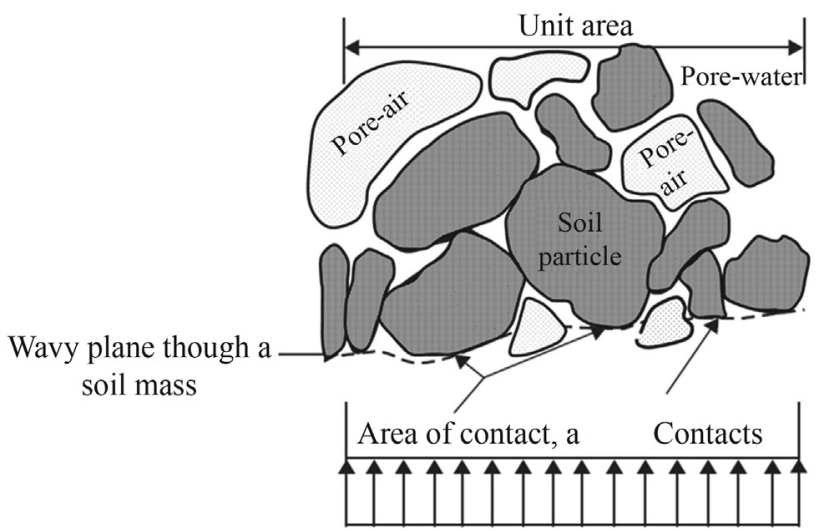

Figure 9 - Wavy plane passed through an unsaturated soil. 
tion that is similar in character to the Bishop (1959) equation.

$$
\sigma^{\prime}=\left(\sigma-u_{a}\right)+S\left(u_{a}-u_{w}\right)
$$

The question remains, "Can a wavy plane analysis be used as a proof for an effective stress equation?" The answer would appear to be "no" because a plane, (and particularly a wavy plane), does not constitute a legitimate freebody diagram. Or it can be stated that a wavy plane does not incorporate spatial variation and as a result it cannot be considered to be a legitimate free-body diagram.

The superposition of coincident equilibrium stress fields associated with the independent phases of a multiphase medium would appear to provide a more convincing explanation for the selection of independent stress state variables for multiphase materials.

12.2. What is the fundamental difficulty associated with the use of an equation to describe the stress state for an unsaturated soils?

The term, effective stress, $\left(\sigma-u-_{w}\right)$, was originally defined for a saturated soil and became part of a stress tensor that described the stress state for the soil structure. Attempts to generate a so-called effective stress equation for an unsaturated soil have always resulted in the incorporation of a soil property into the attempt to describe the stress state. Soil properties are unacceptable in the description of stress state based on the fundamental principles of continuum mechanics.

Incorporating soil properties into the description of stress state also imposes serious inflexibility with respect to the development of a range of required constitutive equations and subsequent formulations. This is particularly true when attempting to account for behavioural effects such as nonlinearity and hysteresis. Geotechnical engineers must decide whether or not it is important to adhere to the fundamental principles of continuum mechanics or strike off on another course of action. In this sense, the decision becomes philosophical in nature.

Morgenstern (1979) in his comments titled, Properties of Compacted Soils, published in the proceedings of the $6^{\text {th }}$ Pan-American Conference on Soil Mechanics and Foundation Engineering in Lima, Peru, explained his concerns about the use of an equation containing soil properties to describe the stress state of an unsaturated soil. He pointed out that Bishop's effective stress equation has "proved to have little impact on practice. The parameter, $\chi$, when determined for volume change behaviour was found to differ when determined for shear strength. While originally thought to be a function of degree of saturation and hence bounded by 0 and 1 , experiments were conducted in which $\chi$ was found to go beyond these bounds. The effective stress is a stress variable and hence related to equilibrium considerations alone". Morgenstern went on to explain that $\mathrm{Bi}$ shop's effective stress equation "contains the parameter, $\chi$, that bears on constitutive behaviour. This parameter is found by assuming that the behaviour of a soil can be expressed uniquely in terms of a single effective stress variable and by matching unsaturated soil behaviour with saturated soil behaviour in order to calculate $\chi$. Normally, we link equilibrium considerations to deformations through constitutive behaviour and do not introduce constitutive behaviour into the stress state".

Once the effective stress equation becomes constitutive in character, it must be faced with the rigorous tests of uniqueness for usage in engineering practice. It would appear that the need for an effective stress equation can easily be replaced through use of independent stress tensors containing stress state variables. However, there continues to be ongoing attempts to revert to the usage of an effective stress equation. The use of an effective stress equation for unsaturated soils violates the basic assumptions inherent in classical continuum mechanics and places serious constraints on subsequent formulations. These concerns can be circumvented through the use of independent stress state variables for the proposal of shear strength, volume change and other constitutive relations for the practice of unsaturated soil mechanics (Fredlund \& Rahardjo, 1993; Fredlund et al., 2012).

It would appear that the issues related to the description of the stress state in an unsaturated soil can only be resolved through an understanding and acceptance of the independent roles of state variables and constitutive behaviour within the context of continuum mechanics. The basis for stress state variables for an unsaturated soil is the same as those explained for a saturated soil. In other words, consideration of force equilibrium for each phase of an unsaturated soil provides the basis for the selection of appropriate independent stress state variables. The important equations that must be given consideration are Newton's equilibrium equations in three coordinate directions. The search needs to focus on variable(s) that qualify as state variables. These variables need to be placed into the tensor form and in so doing will provide a strong science basis for the formulation of unsaturated soil mechanics theories.

\section{Theoretical Basis for Independent Stress State Variables}

Fredlund \& Morgenstern (1977) provided a theoretical justification for independent stress state variables based on a continuum mechanics approach. The independent stress state variables were then used in the formulation of constitutive models for all the classic application areas of unsaturated soil mechanics. Engineering problems were solved based on constitutive models and theoretical derivations that utilized independent stress state variables. This information was subsequently synthesized in two books on unsaturated soil mechanics; namely, Soil Mechanics for Unsaturated Soils (1993) by D.G. Fredlund \& H. Rahardjo, 
and Unsaturated Soil Mechanics in Engineering Practice (2012) by D.G. Fredlund et al.

It would appear that fundamentally, "state variables" are embedded within the conservative laws of physics. The conservation of mass dictates the form and number of "deformation state variables" required to map the movement of independent phases of a multiphase system. The conservation of energy (or momentum) dictates the form and number of "stress state variables" and "thermal state variables" required for equilibrium considerations of a multiphase system (e.g., an unsaturated soil).

The general procedure outlined for the determination of the stress tensor for the soil structure of a saturated soil can also be used for consideration of an unsaturated soil. While the saturated soil constituted a two phase system, an unsaturated soil needs to be considered as a four phase system. In addition to the soil solids (i.e., soil structure), water phase and air phase, the contractile skin needs to be recognized as a fourth independent phase (Wang \& Fredlund, 2003). The need for the contractile skin to be recognized as a fourth phase can be visualized by observing the changes in volume that can occur (i.e., changes in the volume defined by the soil structure), as a soil is dried under conditions where total stresses remain constant. Under this condition, volume changes are due to the shrinkage imposed by the air-water interface. The air-water interface is commonly referred to as the contractile skin.

An unsaturated soil can be visualized as having two phases that behave as solids; namely, the soil solids and the contractile skin (Wang \& Fredlund, 2003). These phases qualify as solids within the continuum mechanics sense since they can come to equilibrium under the application of a stress gradient. The unsaturated soil also has two phases that qualify as fluids; namely, water and air. These phases qualify as fluids in the sense that they do not come to equilibrium under the application of a stress gradient.

An unsaturated soil has four phases and as a result, four independent equilibrium equations can be written. An equilibrium equation can also be written for the overall combination of the four phases and it will take the form of Eqs. 8, 9, and 10. There are only four independent equations that can be written. Equilibrium equations can also be formed through the combination of one or more phases as illustrated by Fredlund \& Morgenstern (1977). Fredlund (1973) also showed that the equations describing the equilibrium of the soil structure were yielded the same stress state variables for the equilibrium of the contractile skin. In other words, the stress state variables that produce equilibrium for the soil solids (i.e., soil structure) also produce equilibrium for the contractile skin.

\subsection{Equilibrium of soil structure for an unsaturated soil element}

The equilibrium of the soil structure in the $y$-direction can be written as the difference between the total equilib- rium equation and the sum of the water, air and contractile skin equilibrium equations. The following equation is obtained when using the air phase as a reference phase during the derivation of the equilibrium equation for the soil structure.

$$
\begin{aligned}
& \frac{\partial \tau_{x y}}{\partial x}+\frac{\partial\left(\sigma_{y}-u_{a}\right)}{\partial y}+\left(n_{w}+n_{c} f^{*}\right) \frac{\partial\left(u_{a}-u_{w}\right)}{\partial y}+ \\
& \frac{\partial \tau_{z y}}{\partial z}+\left(n_{c}+n_{s}\right) \frac{\partial u_{a}}{\partial y}+n_{s} \rho_{s} g- \\
& F_{s y}^{w}-F_{s y}^{a}+n_{c}\left(u_{a}-u_{w}\right) \frac{\partial f^{*}}{\partial y}=0
\end{aligned}
$$

where $n_{a}=$ porosity with respect to the air phase, $n_{w}=$ porosity with respect to the water phase, $n_{c}=$ porosity with respect to the contractile skin, $f^{*}=$ interaction function between the contractile skin and the soil structure, $F_{s y}{ }^{a}=$ interaction body force between the solids and the air phase in the $y$-direction, and $F_{s y}{ }^{w}=$ interaction body force between the solids and the water phase in the $y$-direction.

Similar equations can be written for the $x$ - and $z$-directions, respectively:

$$
\begin{aligned}
& \frac{\partial\left(\sigma_{x}-u_{a}\right) \tau_{x y}}{\partial x}+\left(n_{w}+n_{c} f^{*}\right) \frac{\partial\left(u_{a}-u_{w}\right)}{\partial x}+\frac{\partial \tau_{y x}}{\partial y}+ \\
& \frac{\partial \tau_{z x}}{\partial z}+\left(n_{c}+n_{s}\right) \frac{\partial u_{a}}{\partial x}-F_{s x}^{w}-F_{s x}^{a}+ \\
& n_{c}\left(u_{a}-u_{w}\right) \frac{\partial f^{*}}{\partial x}=0
\end{aligned}
$$

where $F_{s x}{ }^{a}=$ interaction body force between the solids and the air phase in the $x$-direction, and $F_{s x}{ }^{w}=$ interaction body force between the solids and the water phase in the $x$-direction.

$$
\begin{aligned}
& \frac{\partial \tau_{x z}}{\partial x}+\frac{\partial \tau_{y z}}{\partial y}+\frac{\partial\left(\sigma_{z}-u_{a}\right)}{\partial z}+\left(n_{w}+n_{c} f^{*}\right) \frac{\partial\left(u_{a}-u_{w}\right)}{\partial z}+ \\
& \left(n_{c}+n_{s}\right) \frac{\partial u_{a}}{\partial z}-F_{s z}^{w}-F_{s z}^{a}+n_{c}\left(u_{a}-u_{w}\right) \frac{\partial f^{*}}{\partial y}=0
\end{aligned}
$$

where $F_{s z}{ }^{a}=$ interaction body force between the solids and the air phase in the $z$-direction, and $F_{s z}{ }^{w}=$ interaction body force between the solids and the water phase in the $z$-direction.

The stress variables controlling the equilibrium of the soil structure are the stress state variables that control the mechanical behavior of soils. There are three independent sets of normal stresses, (i.e., surface tractions) that can be extracted from the equilibrium equations for the soil structure to form the stress state variables. The three stress state variables are: $\left(\sigma-u_{a}\right),\left(u_{a}-u_{w}\right)$, and $\left(u_{a}\right)$. The stress variable, $u_{a}$, is also a stress state variable but can be eliminated if the soil particles are assumed to be incompressible. Therefore, 
the stress state variables for the soil structure and the contractile skin in an unsaturated soil are $\left(\sigma-u_{a}\right)$ and $\left(u_{a}-u_{w}\right)$.

The stress state variables act in three Cartesian coordinate directions and the variables can be collected to form two independent stress tensors. The two independent stress tensors can be written as the stress state at a point in an unsaturated soil.

$$
\begin{aligned}
& {\left[\begin{array}{ccc}
\left(\sigma_{x}-u_{a}\right) & \tau_{y x} & \tau_{z x} \\
\tau_{x y} & \left(\sigma_{y}-u_{a}\right) & \tau_{z y} \\
\tau_{x z} & \tau_{y z} & \left(\sigma_{z}-u_{a}\right)
\end{array}\right]} \\
& {\left[\begin{array}{ccc}
\left(u_{a}-u_{w}\right) & 0 & 0 \\
0 & \left(u_{a}-u_{w}\right) & 0 \\
0 & 0 & \left(u_{a}-u_{w}\right)
\end{array}\right]}
\end{aligned}
$$

Equation 27 is referred to as the net normal stress tensor and Eq. 28 is referred to as the matric suction (or soil suction) tensor. The pore-air pressure appears in both stress tensors; however, it is the difference between stress components that allows the two tensors to qualify as independent stress state variables. The stress variables in Eqs. 27 and 28 can be placed on the surface of a cube to give the stress state at a point as shown in Fig. 10.

As an unsaturated soil approaches saturation, the degree of saturation, $S$, approaches $100 \%$. The pore-water pressure, $u_{w}$, approaches the pore-air pressure, $u_{a}$, and the matric suction term, $\left(u_{a}-u_{w}\right)$, goes towards zero. The second stress tensors for the unsaturated soil disappear because the matric suction, $\left(u_{a}-u_{w}\right)$, becomes zero. It should be noted that it is not necessary for the pore-water pressure to go to zero in order for the soil to behave as a saturated soil. Rather, it is necessary for the pore-water pressure to increase until it becomes equal to the pore-air pressure and then the soil behaves as a saturated soil.

Only the first stress tensor is left to represent the stress state for a saturated soil once the pore-water pressure is equal to pore-air pressure. The pore-air pressure term in the first stress tensor becomes equal to the pore-water pres-

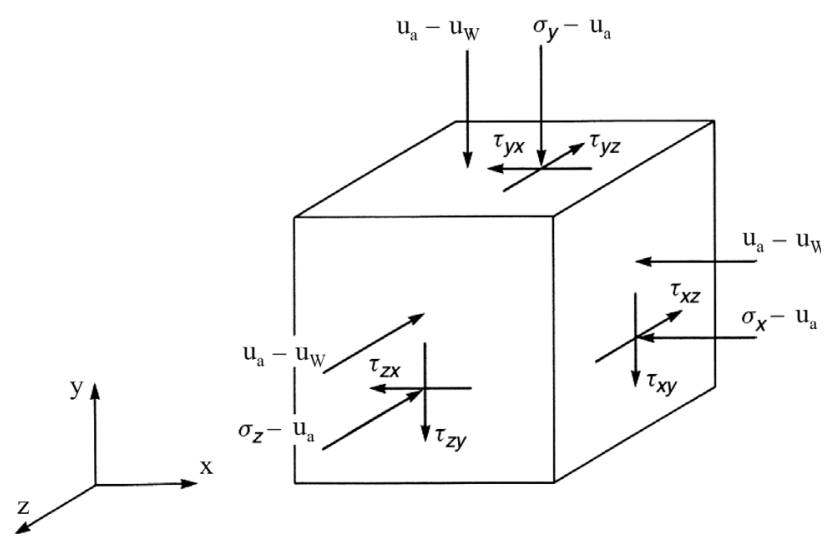

Figure 10 - Stress state at a point for the soil structure and the contractile skin in an unsaturated soil. sure, $u_{w}$, as the soil becomes saturated. The stress state at a point in a saturated soil was illustrated in Fig. 7. The stress tensor for a saturated soil is consistent with that presented by Terzaghi (1936) as the effective stress variable, $\left(\sigma-u_{w}\right)$.

\subsection{Other combinations of stress state variables}

The soil structure equilibrium equations can have three different forms depending upon the reference phase used during the derivation of the equilibrium equations. Equations 24, 25, and 26 are the resulting equations when using the air phase as the reference phase during the derivation. Other forms of the derivation can use the water phase or else the total stress field as a reference. Each form of the equilibrium equations contains a combination of two stress state variables. In other words, any two of three possible stress variables, (i.e., $\left(\sigma-u_{a}\right),\left(\sigma-u_{w}\right)$, and $\left.\left(u_{a}-u_{w}\right)\right)$, can be used to describe the stress state for the soil structure and contractile skin in an unsaturated soil.

\section{The Principle or Concept Associated with Stress State Variables}

The principle or concept associated with stress state variables can be stated as follows: "If one or more of the stress state variables are changed, the equilibrium of the system is disturbed and changes in the system can be anticipated, and vice versa". The same principle applies to both the soil structure and the contractile skin.

\section{Visualization of the World of Soil Mechanics Based on Stress State Variables}

Figure 11 illustrates the transition in the description of the stress state when moving from a saturated soil to an unsaturated soil (and vice versa), (Fredlund, 1994). The transition is shown to occur at the water table or the point at which the pore-water pressures change from a positive value to a negative value. There is a zone immediately above the water table referred to as the capillary zone. This zone may be essentially saturated; however, it is suggested

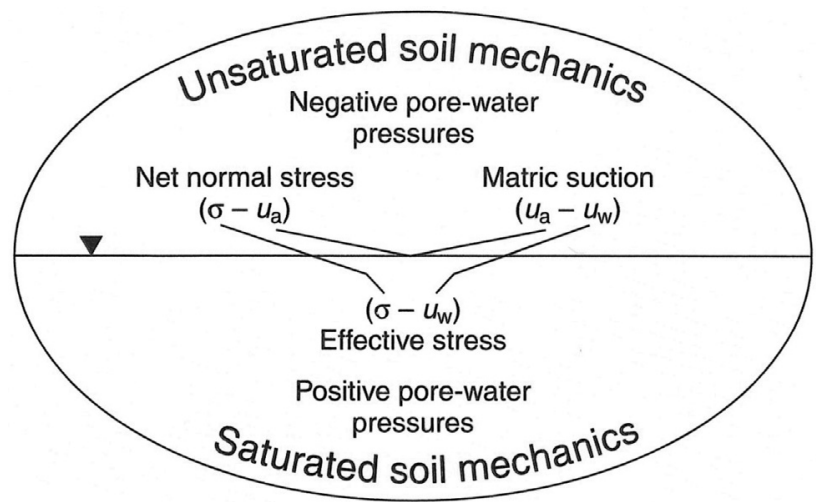

Figure 11 - Visualization of the world of soil mechanics in terms of the description of the stress state for saturated and unsaturated soils (Fredlund, 1996). 
that the transition between saturated soil mechanics and unsaturated soil mechanics is best based on whether the porewater pressures are positive or negative.

Numerous problems in soil mechanics are analyzed using a one-dimensional analysis with total stresses being changed in the vertical direction. Consequently, an increase in stresses in the vertical direction produces a tendency for deformation in the horizontal direction as well as the (downward) vertical direction. On the other hand, a decrease in the pore-water pressure will produce a tendency for shrinkage in all three directions. Only under isotropic total stress conditions will the deformation directions be similar for total stress and pore-water pressure changes. Consequently, it would appear to be reasonable to acknowledge the independent behaviour of changes in the total stress field from that of the pore-water pressure field when moving above the water table. The above conceptual picture is a reminder that changes in total stresses and changes in pore-water pressures can produce different deformation fields in an unsaturated soil. Therefore, the net normal stress variable needs to be considered as being independent of the matric suction variable for analytical purposes. Also, the magnitude of deformations associated with changes in net total stress may be different from the magnitude of deformations associated with changes in matric suction. Fig- ure 12 provides a visualization tool that illustrates the difference in the stress state at a point when the soil is saturated and unsaturated.

\section{Recommendations for the Ongoing Development of Unsaturated Soil Mechanics}

Following are a series of suggested recommendations for the development of a continuum mechanics based approach to the development of unsaturated soil mechanics.

1) That the term "effective stress" should be limited to the original definition described by Terzaghi (1936) for saturated soils.

2) The concepts of stress state variables as defined in continuum mechanics should be adopted as the science basis for unsaturated soil mechanics.

3) Stress state variables for any soil should be kept independent of the material properties.

4) There can be multiple stress state variables (and deformation state variables) for a multiphase material.

5) Temperature and time should also be considered as state variables, in addition to deformation state variables.

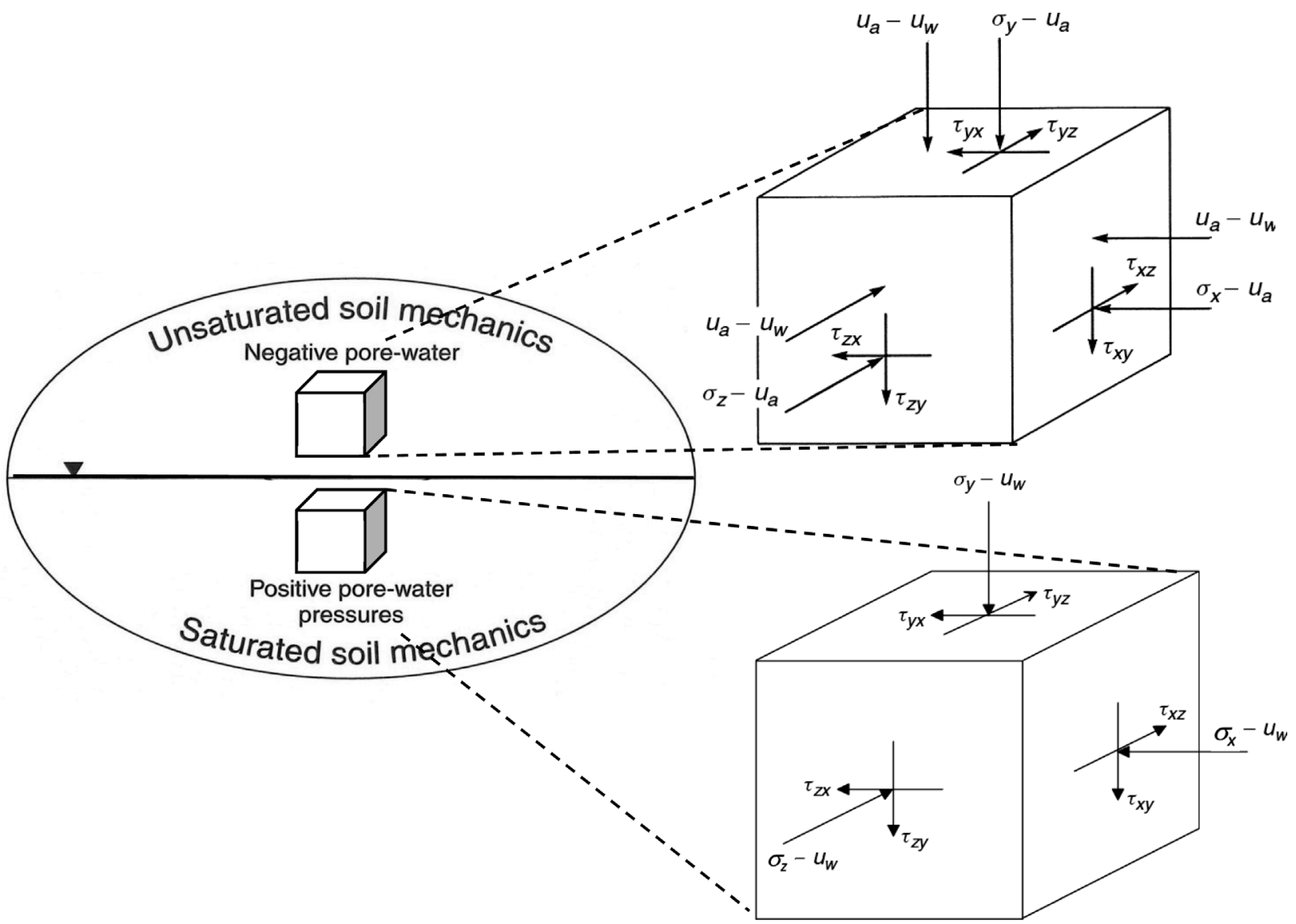

Figure 12 - Visualization of the stress state at a point for saturated and unsaturated soils (Fredlund, 1996). 


\section{Incorporation of Soil Properties into the Definition of Stress State}

Skempton (1961) felt that it was of "philosophical interest to examine the fundamental principles of effective stress, since it would seem improbable that an expression of the form" proposed by Terzaghi, "is strictly true." He went on to say, "We may therefore anticipate that, even for fully saturated porous materials, the general expression for effective stress is more complex, and that Terzaghi's equation has the status of an excellent approximation in the special case of saturated soils." He goes on to say that "the effective stress is actually the intergranular stress acting between the particles" and the effective stress should be corrected for the area of contact between the particles.

Skempton's (1961) statements did not recognize the need for multiple stress state variables in some situations (e.g., the case of a saturated soil with compressible soil particles). His search opened the way for introducing material properties into the description of stress state. The so-called refinement associated with the "area of contact" between soil particles did not have a significant impact in saturated soil mechanics but it set the stage for other considerations related to effective stress for volume change and shear strength of saturated and unsaturated soils.

Nur \& Byerlee (1971) went through a similar exercise in attempting to develop an "exact effective stress law for elastic deformation of rock with fluids". In coming to the conclusion that Terzaghi's equation "is an excellent approximation", they failed to realize the need for multiple stress state variables for the situation involving compressible materials.

\subsection{Soil properties in effective stress equations for sat- urated soils}

Consideration of the area of contact between soil particles set the stage for suggestions that there was a "more correct expression" for effective stress equation that could be written for analyzing shear strength problems. Equation 29 was suggested as the effective stress equation for "fully saturated materials" (Skempton, 1961).

$$
\sigma^{\prime}=\sigma-\left(1-\frac{a \tan \psi}{\tan \varphi^{\prime}}\right) u_{w}
$$

where $a=$ area of contact between particles, $\Psi=$ angle of intrinsic friction of the solid particles, and $\varphi^{\prime}=$ angle of internal friction between the soil particles.

An independent effective stress equation was suggested for the analysis of volume change problems involving saturated soils (Skempton, 1961).

$$
\sigma^{\prime}=\sigma-\left(1-\frac{C_{s}}{C}\right) u_{w}
$$

where $C_{s}=$ compressibility of the solids, and $C=$ compressibility of the porous material or the soil structure.

Laughton (1955) performed experiments on materials with compressible particles. The results can be interpreted as showing the need for a second independent state variable (i.e., $u_{w}$ ), when dealing with compressible materials.

The need for separate effective stress equations when analyzing shear strength and volume change problems would appear to be surprising if the equations are truly a description of "stress state". The volume change analysis of materials with compressible solids can be analyzed without the need for a new effective stress equation if it is realized that two independent stress state variables are required; namely, the Terzaghi effective stress variable $\left(\sigma-u_{w}\right)$ and pore-water pressure, $\left(u_{w}\right)$. There is no need for two effective stress equations (i.e., one for shear strength and another for volume change). All material properties must be incorporated at the constitutive behaviour level of formulations that describe soil behaviour.

Nur \& Byerlee (1971) incorporated the compressibility properties into their attempt to develop a more "exact expression for an effective stress law" for the study of elastic deformations of rock materials. Their statement that "there is a great deal of disagreement on the theoretical accuracy and validity of Terzaghi's relation" would appear to be an overstatement. Bringing compressibility values into the effective stress equation is not necessary if it is recognized that a compressible particulate soil or rock requires an independent stress state variable in this situation; namely, an isotropic pore-water pressure tensor.

A summary of so-called proposed refinements to Terzaghi's effective stress equation has been given by Gens (2005). The proposed refinements are not repeated herein because there appears to be no fundamental reason to accept soil properties into the description of stress state.

\subsection{Soil properties in effective stress equations for un- saturated soils}

With a history of incorporating soil properties into effective stress equations for saturated soils, it is not that surprising that soil properties should find their way into an effective stress equation for unsaturated soils. Bishop (1959) introduced the $\chi$ parameter into his proposed effective stress equation for unsaturated soils. The $\chi$ parameter was found to generally be a nonlinear function of degree of saturation. Later, the degree of saturation variable, $S$, was substituted for the $\chi$ parameter by some researchers Bishop's (1959) equation became referred to as the average skeleton stress.

$$
\sigma^{\prime}=\left(\sigma-u_{a}\right)+S\left(u_{a}-u_{w}\right)
$$

The history of various forms for the effective stress for an unsaturated soil has been summarized by Gens (2005) and is not repeated herein. 
Khalili \& Khabbaz (1998) suggested that the $\chi$ parameter could be related to the air-entry value for an unsaturated soil. The soil-water characteristic curve, SWCC, for desorption of a soil was set as a demarcation between saturated and unsaturated soil behaviour. Unsaturated soil behaviour was related to degree of saturation through use of a second soil parameter, $m$, which was set to 0.55 .

It is apparent that the search for an effective stress equation for unsaturated soil behavior had its origin in the incorporation of soil properties into Terzaghi's effective stress equation. This constitutes a fundamental deviation from the context of continuum mechanics.

There have been several researchers who have proposed and advocated the use of independent stress state variables. Fredlund \& Morgenstern (1977) used equilibrium considerations of a multiphase system to illustrate the source for acceptable, independent stress state variables. Null type laboratory tests were also used to confirm the suitability of two independent stress state variables for unsaturated soils. There are other researchers who previously suggested using independent stress state variables. Biot's (1941), in his proposed theory of consolidation advocated the use of two independent stress variables for unsaturated soils. Others who supported this approach are Coleman (1962) and Matyas \& Radhakrishna (1968). Bishop \& Blight (1963) also presented laboratory measured constitutive data using two independent stress state variables.

In his notes on effective stresses Gens (2005) concludes, "The description of the behaviour of unsaturated soils requires the use of two independent stress variables". The author agrees with the direction advocated and would add that there ought to not be an ongoing search for a universal effective stress expression for unsaturated soils. Such a search appears to always lead to the inclusion of soil properties, making the stress state expressions "constitutive" in character.

Theoretical formulations for unsaturated soils problems have been proposed that maintained the separation of state variables and constitutive equations. These formulations have also been solved for a variety of saturatedunsaturated soils problems common to geotechnical engineering (Fredlund \& Rahardjo (1993) and Fredlund et al. (2012)). The solutions have been used extensively in solving geotechnical engineering problems. It is the soil-water characteristic curves, SWCCs, (i.e., desorption and adsorption branches) that have proved to provide the primary unsaturated soils information required for each of the formulations. Sheng et al. (2008) also demonstrated that it was possible to formulate a critical state model for unsaturated soils while maintaining the separation of state variables and constitutive behaviour.

\section{Grounds for a Connection Between the Two Approaches to Formulating Unsaturated Soil Mechanics}

It is of interest to examine the possible grounds for a compromise between the two procedures that have been proposed for formulating unsaturated soil mechanics problems. The relationship between the two approaches can be viewed as follows from an elementary standpoint.

Let us start with the use of two independent stress state variables for an unsaturated soil and then try to formulate an acceptable constitutive relationship. Let us consider the volume change of an unsaturated soil where the difference in behaviour associated with changing net total stress and matric suction is uniquely related to the degree of saturation of the soil. It would then be possible to write the following general volume change equation with constant, linear soil properties.

$$
\mathrm{d} v=m_{l}^{s}\left(\sigma-u_{a}\right)+m_{l}^{s} S\left(u_{a}-u_{w}\right)
$$

where $\mathrm{d} v=$ soil structure volume change, $\left(\sigma-u_{a}\right)=$ net total stress state variable, $\left(u_{a}-u_{w}\right)=$ matric suction variable, $m_{l}^{s}=$ compressibility of the soil structure with respect to the $\left(\sigma-u_{a}\right)$ stress state variable, and $S=$ degree of saturation of the soil.

Equation 32 states that the relationship between changing the net total stress and the matric suction variables can be approximated through use of the degree of saturation variable. Equation 32 is an acceptable form for a constitutive relationship. However, it may not be sufficiently general to embrace all unsaturated soil behaviour. Consequently, the use of such an equation may prove to be too restrictive in engineering practice.

Equation 32 also suggests that the degree of saturation is known at all times when simulating a particular process. However, in reality, an independent analysis is generally required to predict water movement in or out of the soil. A transient seepage analysis also requires two nonlinear soil properties for its solution; namely, the hydraulic conductivity and the water storage function. The hydraulic properties in turn may or may not be affected by both stress state variables. It should also be noted that the overall volume and the volume of water in the soil must both be known in order to compute the degree of saturation.

A similar equation can be written for the characterization of shear strength but once again the form may prove to be not sufficiently general for engineering practice. There are also other physical relationships such as the water content constitutive relationship (i.e., the soil-water characteristic curve, SWCC), that does not have a unique response to the degree of saturation.

In general, it would appear to be better to separate state variables from constitutive behaviour in order to provide the greatest flexibility and accuracy in defining unsaturated soil behaviour. 


\section{References}

Aitchison, G.D. (1961). Relationship of moisture and effective stress functions in unsaturated soils. Proc. Pore Pressure and Suction in Soils Conference, Butterworths, London, pp. 47-52.

Biot, M.A. (1941). General theory for three-dimensional consolidation. Journal of Applied Physics, 12(2):155164.

Bishop, A.W. (1959). The principle of effective stress. Teknisk Ukeblad, Norwegian Geotechnical Institute, 106(39):859-863 (Lecture delivered in 1955).

Bishop, A.W. \& Blight, G. E. (1963). Some aspects of effective stress in saturated and unsaturated soils. Geotechnique, 13(3):177-197.

Croney, D.; Coleman, J.D. \& Black, W.P.M. (1958). Movement and distribution of water in soil in relation to highway design and performance. In: Water and Its Conduction in Soils, Highway Research Board, Special Report, Washington, DC, No. 40, pp. 226-252.

Coleman, J.D. (1962). Stress/strain relations for partly saturated soils. Geotechnique, 12(4):348-350.

Fredlund, D.G. (1973). Volume Change Behaviour of Unsaturated Soils. PhD Thesis, Department of Civil Engineering, University of Alberta, Edmonton.

Fredlund, D. G. \& Rahardjo, H. (1993). Soil Mechanics for Unsaturated Soils. John Wiley \& Sons, New York, $507 \mathrm{p}$.

Fredlund, D.G. (1994). Visualization of the world of soil mechanics. Proceedings of the Sino-Canadian Symposium on Unsaturated/Expansive Soils, Wuhan, China, pp. 1-21.

Fredlund, D.G. \& Morgenstern, N.R. (1977). Stress state variables for unsaturated soils. Journal of Geotechnical Engineering Division, ASCE, 103(GT5):447-466.

Fredlund, D.G.; Rahardjo, H. \& Fredlund, M.D. (2012). Unsaturated Soil Mechanics in Engineering Practice. John Wiley \& Sons, New York, 926 p.

Fung, Y.C. (1965). Foundations of Solid Mechanics. Prentice-Hall, Englewood Cliffs, 525 p.

Fung, Y.C. (1977). A First Course in Continuum Mechanics. Second Edition. Prentice-Hall, Englewood Cliffs, $311 \mathrm{p}$.

Gens, A. (2005). Effective stresses. First MUSE School, (Mechanics of Unsaturated Soils for Engineering), Fun- damentals of Unsaturated Soils, (PowerPoint), Universitat Politecnica de Catalunya, Barcelona.

Jennings, J.E. (1961). A revised effective stress law for use in the prediction of the behaviour of unsaturated soils. Proc. Conference on Pore Pressure and Suction in Soils, London, England, pp. 26-30.

Jommi, C. (2000). Remarks on the constitutive modeling of unsaturated soils. In: Experimental Evidence and Theoretical Approaches in Unsaturated Soils, A. Tarantino, and C. Mancuso (eds), Rotterdam, Balkema, pp. 139153.

Khalili, N. \& Khabbaz, M.H. (1998). A unique relationship for $\chi$ for the determination of the shear strength of unsaturated soils. Geotechnique, 48(5):681-687.

Laughton, A.S. (1955). The Compaction of Ocean Sediments. PhD Thesis, University of Cambridge, Cambridge, U.K.

Matyas, E.L. \& Radhakrishna, H.S. (1968). Volume change characteristics of partially saturated soils. Geotechnique, 18(4):432-448.

Morgenstern, N.R. (1979). Properties of compacted soils. Proc. Sixth Pan-American Conference on Soil Mechanics and Foundation Engineering, Lima, Peru, v. 3, pp. 349-354.

Nur, A. \& Byerlee, J.D. (1971). An exact effective stress law for elastic deformation of rock with fluids. Journal of Geophysical Research, 76(26):6414-6419.

Sheng, D.; Fredlund, D.G. \& Gens, A. (2008). A new modelling approach for unsaturated soils using independent stress variables. Canadian Geotechnical Journal, 45(4):511-534.

Skempton, A.W. (1961). Effective stress in soils, concrete and rocks. Proc. Conference on Pore Pressure and Suction in Soils, Butterworths, London, pp. 4-16.

Terzaghi, K. (1936). The shear strength of saturated soils. Proc. First International Conference on Soil Mechanics and Foundation Engineering, Cambridge, v. 1, pp. 5456.

Terzaghi, K. (1943). Theoretical Soil Mechanics. John Wiley \& Sons, New York, 528 p.

Truesdell, C. (1966). The Elements of Continuum Mechanics, Springer-Verlag, New York, 280 p.

Wang, Y.H. \& Fredlund, D.G. (2003.) Towards a better understanding of the role of the contractile skin. Proc. Second Asian Conference on Unsaturated Soils, UNSAT-ASIA 2003, Osaka, Japan, pp. 419-424. 